\title{
DESAFIOS FEDERATIVOS PRECISAM SER VENCIDOS PARA ACABAR COM A FALTA D'ÁGUA
}

Coluna publicada em 16.12.2014: <http://www.conjur.com.br/2014-dez-16/ contas-vista-desafios-federativos-vencidos-acabar-falta-dagua $>$

A forte estiagem que tomou conta de boa parte do país neste ano de 2014 trouxe à tona a questão do gerenciamento dos recursos hídricos e do fornecimento de água, serviço público responsável por assegurar um direito fundamental, que integra a dignidade da pessoa humana, até porque indispensável para a própria sobrevivência. Inegável, portanto, a responsabilidade do Estado em atender a essa necessidade pública.

O modo mais adequado e eficiente de fazê-lo, no entanto, depende muito da forma pela qual se estrutura e organiza o Estado, o que é uma tarefa, desnecessário dizer, extremamente complexa.

Complexidade que se intensifica quando é escolhido o modelo federativo, em que o poder se divide territorialmente em unidades autônomas. Isso exige uma delimitação de competências, encargos e recursos, dando origem a uma multiplicidade de relaçõos entre entes federados, órgãos e políticas públicas, que devem se harmonizar com unidade de propósitos para atender a essa e outras necessidades públicas.

Tendo em vista a melhor alocação do fornecimento de bens e serviços públicos, que deve observar as preferências dos cidadãos e adequar-se à limitação espacial da incidência dos benefícios desses bens e serviços, que variam conforme cada caso, o modelo federativo tende a ser mais eficiente na maior parte dos casos, especialmente nos Estados de grande extensão territorial, como é o caso do Brasil.

Vencer as dificuldades sempre presentes para aperfeiçoar esse desenho do Estado é um desafio permanente, tarefa a ser cumprida dia após dia, no Brasil e no resto do mundo. Não é fácil distribuir encargos e financiar políticas públicas com 
uma multiplicidade de entes federados autônomos, cujos governantes são eleitos pela população, no mais das vezes com visões diferentes sobre a melhor forma de gerir a administração pública, e que devem conviver harmonicamente e agir com unidade de propósitos na busca do bem comum.

O fornecimento de água, serviço que se insere no contexto das políticas públicas de gerenciamento de recursos hídricos e de saneamento básico, é daquelas tarefas especialmente complexas, e as dificuldades para organizar o Estado de modo a atender essa necessidade básica da população acabam aparecendo em situações de crise, como a que se está vivenciando.

Está entre aqueles serviços públicos que dificilmente podem ser prestados no âmbito de uma unidade da federação. Exigem, no mais das vezes, uma cooperação federativa não só horizontal, mas também e principalmente vertical, com a participação de entes federados de todos os níveis, e em todos os aspectos - planejamento, execução, financiamento entre outros. $\mathrm{O}$ crescimento das cidades, com o surgimento das megalópoles e grandes aglomerados urbanos faz com que, em muitos casos, se ultrapasse o conceito de interesse local, tornando necessário o compartilhamento de alguns serviços, nos quais os de fornecimento de água e saneamento se destacam. ${ }^{1}$ As regiōes metropolitanas tornam-se extremamente úteis para viabilizar uma gestão eficiente desse serviço, assim como consórcios públicos, parcerias público-privadas e instrumentos financeiros como fundos e transferências intergovernamentais.

É nesse momento que vemos a importância e a falta que faz um federalismo bem construído, com clara delimitação de competências e encargos, especialmente no que tange aos aspectos financeiros, diretamente afetados por essa estruturação. ${ }^{2}$

Os primeiros registros relevantes de preocupação com o tema no Brasil evidenciam-se com o Plano Nacional de Saneamento (Planasa), em 1971, ${ }^{3}$ que abrangia os serviços de abastecimento de água e esgotamento sanitário. Financiado por recursos de várias fontes, nos termos do Sistema de Financiamento do Saneamento, destacam-se os empréstimos federais concedidos às companhias estaduais de

1 CARVALHO, André Castro. Direito da infraestrutura: perspectiva pública. São Paulo: Quartier Latin, 2014, p. 408-409.

2 Sobre os aspectos e instrumentos financeiros em matéria de saneamento básico, que se relacionam diretamente com o tema, remeto o leitor ao texto CONTI, José Mauricio e CARVALHO, André Castro. Financiamento público da infraestrutura de saneamento básico no Brasil. In: GONZÁLES, Luís Manuel Alonso; TORRES, Heleno Taveira (coords.). Tributos, aguas e infraestructuras. Barcelona: Atelier, 2012, p. 297-320.

3 Regulamentado pelo Decreto 82.587/1978. 
saneamento básico, o que incentivou a transferência dos serviços, inicialmente difusos entre os entes da federação, especialmente municípios, para a esfera estadual, o que se reflete no modelo do sistema atual, e promoveu um avanço, por certo período, nas políticas do setor. ${ }^{4}$

A Constituição de 1988 trata do tema de forma pouco específica, com destaque para o artigo 21, XX, que atribui competência à Uniāo para “instituir diretrizes para o desenvolvimento urbano, inclusive habitação, saneamento básico e transportes urbanos"; artigo 22, IV, que confere competência privativa à União para legislar sobre águas; artigo 23, IX, que prevê ser da competência comum da União, dos estados, do Distrito Federal e dos municípios "promover programas de construção de moradias e a melhoria das condições habitacionais e de saneamento básico"; e artigo 26, I, que inclui entre os bens dos estados "as águas superficiais ou subterrâneas, fluentes, emergentes e em depósito” (g.n.).

Acrescente-se o artigo 30, I e V, que atribui aos municípios competência para legislar sobre assuntos de interesse local e "organizar e prestar, diretamente ou sob o regime de concessão ou permissão, os serviços públicos de interesse local”, e vê-se que o conjunto dos dispositivos citados não permite estabelecer com clareza a titularidade sobre o domínio das águas e o ente competente para prestar o serviço de distribuição. Faz dessa partilha constitucional de atribuições uma questão relativamente complexa, com competências exclusivas e não exclusivas, e competências político-administrativas e legislativas, tornando a titularidade para a prestação de serviços de saneamento o produto de "uma sofisticada conjugação de técnicas de repartição de competências do Estado Federal”, como bem destacado pelo hoje Ministro do STF Luís Roberto Barroso em artigo sobre o tema. ${ }^{5}$

A dificuldade na delimitação das competências, de difícil consenso na doutrina, também transparece na jurisprudência ${ }^{6}$ e, recentemente, voltou a ser debatido em nossa Suprema Corte, ADI 1.842-RJ, em que se constatam as diversas posições sobre o assunto e a complexidade das relações federativas.

Recentemente, o Supremo Tribunal Federal realizou conciliação entre entes federados, na ACO 2.536, movida pelo Ministério Público Federal, em que se

4 BRASIL. IPEA. Infraestrutura social e urbana no Brasil: subsídios para uma agenda de pesquisa e formulação de políticas públicas. Livro 6, v. 2, capítulo 12 - Saneamento básico no Brasil: desenho institucional e desafios federativos. Brasília: IPEA, 2010, p. 503.

5 BARROSO, Luís Roberto. Saneamento básico: competências constitucionais da União, Estados e Municípios. Revista Eletrônica de Direito Administrativo Econômico, n. 11, 2007, p. 4.

6 MARQUES NETO, Floriano de Azevedo. O marco legal do saneamento no Brasil. Revista Trimestral de Direito Público, n. 49/1950, 2005, p. 81. 
discute a possibilidade de realização de obras pelo estado de São Paulo voltadas à captação de águas do rio Paraíba do Sul para tentar amenizar o problema de abastecimento de água, que também banha os estados do Rio de Janeiro e Minas Gerais, o que deixa evidente o conflito federativo presente em matéria de recursos hídricos.

A crise no abastecimento de água que se vê deixa clara a falta de organização e coordenação federativa nesse assunto, mostrando que o federalismo cooperativo brasileiro, em aspectos fundamentais para a atenção aos direitos fundamentais dos cidadãos, é ainda por demais incipiente e tem muito a evoluir.

As políticas públicas que envolvem o fornecimento e distribuição de águas, esgotamento sanitário e gerenciamento de recursos hídricos são um grande desafio para o federalismo cooperativo vigente no Brasil e que, por uma circunstância da natureza, tornaram-se de urgente solução.

Não é o caso de se estender em detalhes, até pela superficial abordagem do tema neste curto espaço, mas é interessante chamar a atenção para alguns aspectos.

De início, note-se que não se pode constatar a falta de legislação sobre o assunto.

A Lei 9.433, de 7 de janeiro de 1997, instituiu a Política Nacional de Recursos Hídricos, criou o Sistema Nacional de Gerenciamento de Recursos Hídricos e tem, entre seus objetivos, "assegurar à atual e às futuras gerações a necessária disponibilidade de água” (art. 20, I), por meio de gestão integrada e planejada, mediante articulação da União com os Estados (art. 4º), compondo o sistema órgãos como o Conselho Nacional de Recursos Hídricos, a Agência Nacional de Águas, os Conselhos de Recursos Hídricos dos Estados e Distrito Federal, os Comitês de Bacias Hidrográficas, as Agências de Águas e outros órgãos dos entes federados (art. 33).

A Lei 11.445, de 5 de janeiro de 2007, estabelece as diretrizes nacionais para o saneamento básico, tendo como um de seus princípios fundamentais o abastecimento de água (art. $2^{\circ}$, III), e nela há dispositivos da maior relevância, como a regulamentação de formas de cooperação, a instituição de fundos para que os entes federados gerenciem de forma compartilhada os recursos (art. 13), o planejamento (art. 19), a regulação (arts. 21 e seguintes), o controle social (art. 47) e as políticas do setor (arts. 48 e seguintes), entre outros. $\mathrm{O}$ artigo 52 determinou à União elaborar o Plano Nacional de Saneamento Básico, sob coordenação do Ministério das Cidades, recentemente aprovado pela Portaria Interministerial 571, de 5 de

Alckmin faz acordo com Rio e Minas, e vai transpor água. O Estado de S.Paulo, 28 de novembro de 2011. 
dezembro de 2013, produzindo o Plansab, com os cenários, diagnósticos, objetivos, estratégias, metas e programas para o setor no curto, médio e longo prazos.

Vê-se não ser por falta - e até mesmo dizer, falha - de legislação que as torneiras estão secando nas nossas casas.

Há até normas em demasia tratando do tema. Mas, o que se vê é não estarem sendo cumpridas - se estivessem, muito provavelmente não faltaria água em lugar algum, basta ler os diversos textos legais que tratam dessa questão e os vários órgãos que deveriam planejar, executar e fiscalizar. Um excesso de normas que, ao serem ignoradas, põe abaixo toda a credibilidade do ordenamento jurídico, inserindo nele uma multiplicidade de comandos que se transformam em letras mortas, sem qualquer efetividade, comprometendo a seriedade de todas as demais normas.

Trata-se de mais um caso em que é preciso dar cumprimento à legislação já existente, tornando real um planejamento que se mostra presente apenas em tese, e utilizar bem os instrumentos de cooperação federativa, especialmente no que tange ao financiamento e compartilhamento de recursos entre os entes federados.

Caso contrário, só nos resta adaptar o ditado popular para reconhecer que "em federação onde falta água, todos brigam e ninguém tem razão", e começar a treinar a dança da chuva... ${ }^{8}$

8 E, quem sabe, se associar aos manifestantes que se reuniram no MASP, em São Paulo, em 21 de novembro de 2014. (Dança da chuva para 39 mil reúne só 200 "torneiras secas". Folha de S.Paulo, p. C6, em 22 de novembro de 2014.) 
